\title{
Disease and pest resistance of endophyte infected and non-infected drunken horse grass
}

\author{
CHUNJIE LI ${ }^{1,2}$, XINGXU ZHANG ${ }^{1}$, FEI LI $^{1}$, ZHIBIAO NAN $^{1 *}$ and C. L. SCHARDL ${ }^{2}$ \\ ${ }^{\prime}$ College of Pastoral Agriculture Science and Technology, Lanzhou University; Key Laboratory of Grassland Argo-Ecosystem, \\ Ministry of Agriculture; Gansu Grassland Ecological Research Institute; 730020 Lanzhou, China; \\ ${ }^{2}$ Department of Plant Pathology, University of Kentucky, Lexington, KY 40546, USA \\ chunjie@lzu.edu.cn
}

\begin{abstract}
The naturally occurring mutualistic symbiosis of Neotyphodium gansuense and drunken horse grass (Achnatherum inebrians) was studied previously in China. In this paper, new data on the interactions of endophyte, host and pathogenic fungi, mite and insect pests are presented. Fungal diseases and pests were examined when test plants were grown in pots in a climate chamber or in the field. There were usually no significant $(\mathrm{P}>0.05)$ differences in the levels of powdery mildew infection (caused by Blumeria graminis) under climate chamber conditions; the only exception was that E+ plants had significantly less powdery mildew infection at $50 \%$ soil water holding capacity (WHC) than at $30 \%$ WHC. There was no significant difference $(\mathrm{P}<0.05)$ in the levels of infection of E- and E+ plants with leaf spot disease, caused by Bipolaris sorokiniana, under field conditions. Regardless of whether grown under growth chamber or field conditions, densities of the mite Tetranychus cinnabarinus on $\mathrm{E}+$ grass were significantly $(\mathrm{P}<0.05)$ lower than that on E- grass. Densities of the bird-cherry-oat aphid (Rhopalosiphum padi) on $\mathrm{E}+$ grass were significantly $(\mathrm{P}<0.05)$ lower than that on E- grass.
\end{abstract}

Keywords: Neotyphodium gansuense, Achnatherum inebrians, diseases, pests, resistance, endophytes

\section{Introduction}

Neotyphodium and Epichloë endophytes have been shown to confer enhanced fitness by increasing drought tolerance, and protecting the host plant against certain nematodes, fungal pathogens, insect herbivores and mammalian herbivores (Siegel et al. 1987; Latch 1993; Schardl \& Phillips 1997). There is some evidence that colony growth of plant-pathogenic fungi is inhibited by Neotyphodium endophytes (White \& Cole 1985; Christensen et al. 1991; Christensen \& Latch 1991; Christensen 1996; Holzmann-Wirth et al. 2000), and that disease tolerance or resistance can be imparted by some but not all Neotyphodium species (West et al. 1989; Gwinn \& Gavin 1992; Welty et al. 1991; Nan \& Li 2000; Wheatley et al. 2000; Trevathan 1996; Blank et al. 1993; Funk et al. 1994; Hume et al. 1997).

Deterring herbivores from feeding on the host grass is one of the most beneficial features of endophytes (Siegel et al. 1987; Latch 1993; Nan \& Li 2004; Popay \& Bonos 2005). So far, at least 50 species in 35 genera have been shown to be deterred from feeding on endophyte-infected grasses (Siegel et al. 1987; Latch 1993; Popay et al. 2000; Nan \& Li 2004; Popay \& Bonos 2005).

The symbiotic association of Neotyphodium gansuense and Achnatherum inebrians is distributed widely in China, and can be found under harsh conditions such as arid or semi-arid and alpine or subalpine grasslands (Li et al. 2004a,b). Endophyte infected $A$. inebrians has been shown to contain high levels of the ergot alkaloids, ergonovine and lysergic acid amide (Miles et al. 1996; Li et al. 2006). Dual-culture testing and inoculation of detached leaves have shown that $N$. gansuense can inhibit growth and disease lesion development by some fungal pathogens ( $\mathrm{Li}$
2005). Our previous investigation included six diseases of $A$. inebrians: seedling rot (Alternaria alternata), rust (Puccinia stipae-sibiricae), powdery mildew (Blumeria graminis), smut (Ustilago hypodytes), leaf spot (Bipolaris sorokiniana) and ergot (Sphacelia sp.) (Li et al. 2003). To explore possibilities of utilising $N$. gansuense for bio-control, this research aimed to determine whether or not endophyte infection reduces the activity of naturally occurring diseases and pests of $A$. inebrians.

\section{Materials and Methods}

Seeds of Achnatherum inebrians were collected from Sangke grassland, Gansu province, China, and kept under constant $5{ }^{\circ} \mathrm{C}$ storage at the Official Forage Seed Testing Center of Ministry of Agriculture, Lanzhou, China.

Endophyte infected seeds were heat treated at a high moisture content to obtain E- seeds ( $\mathrm{Li} 2005$ ). Treated seeds were sown in plastic baskets. Endophyte status was detected by microscopy of samples from 4-week-old seedlings stained with $0.8 \%$ aniline blue.

In a climate chamber, E+ or E- plants were transplanted individually into plastic pots, and were watered regularly and weighed to maintain soil moisture content at 30 or $50 \%$ WHC; i.e. drought and normal growth conditions, respectively. E+ and E- seedlings were also transplanted into the field to establish trial plots under rain-fed conditions. Incidence of the naturally
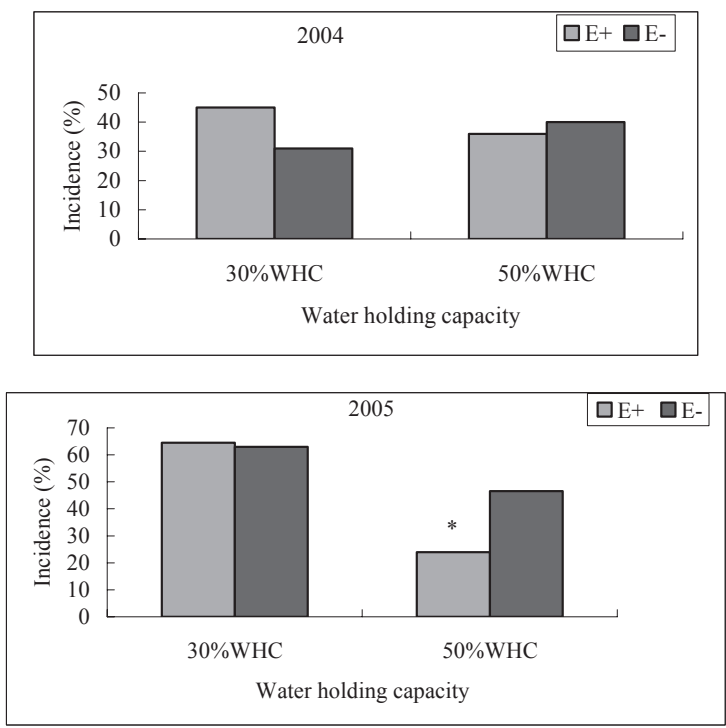

Figure 1 Effects of powdery mildew (B. graminis) on $\mathrm{E}+$ and $\mathrm{E}-\mathrm{A}$. inebrians at $30 \%$ and $50 \%$ WHC soil moisture content in pot conditions. ${ }^{*}$ Differences are significant between $\mathrm{E}+$ and $\mathrm{E}$ - plants $(\mathrm{P}<0.05)$. 


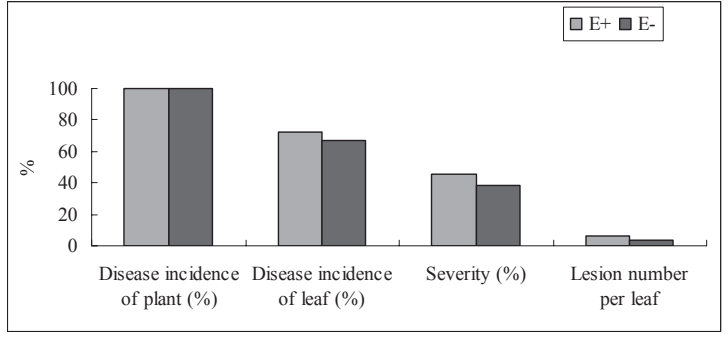

Figure 2 Incidence of $\mathrm{E}+$ and $\mathrm{E}-A$. inebrians leaf spot ( $B$. sorokiniana) under field conditions.

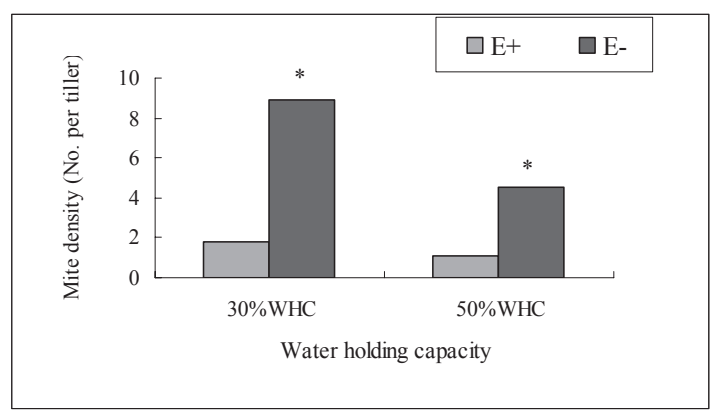

Figure 3 Density of $T$. cinnabarinus on $A$. inebrians under soil moisture content of $30 \%$ and $50 \%$ water holding capacity in greenhouse pot conditions. ${ }^{*}$ Differences are significant between $E+$ and $E$ - plants $(P<0.05)$.

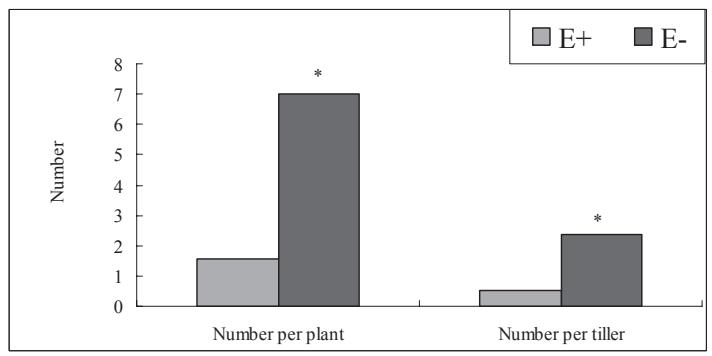

Figure 4 Density of $R$. padi on $\mathrm{E}+$ and $\mathrm{E}-A$. inebrians under field conditions. *Differences are significant between E+ and E- plants $(P<0.05)$.

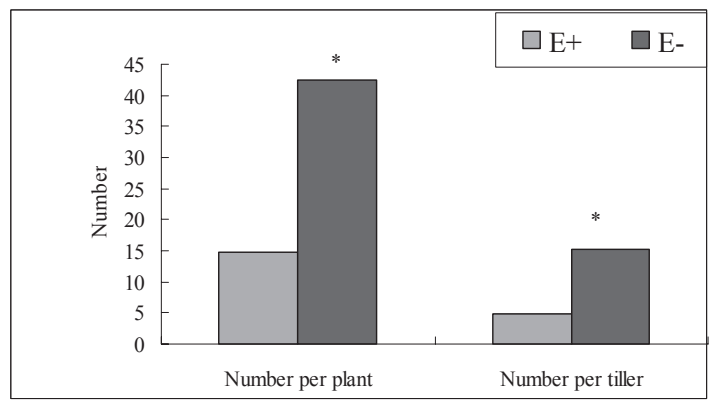

Figure 5 Density of $T$. cinnabarinus on $\mathrm{E}+$ and $\mathrm{E}-A$. inebrians under field conditions. *Differences are significant between $\mathrm{E}+$ and $\mathrm{E}$ - plants $(\mathrm{P}<0.05)$. occurring diseases powdery mildew (Blumeria graminis) and leaf spot (Bipolaris sorokiniana), and numbers of mites (Tetranychus cinnabarinus) and bird-cherry-oat aphids (Rhopalosiphum padi) damage were investigated.

\section{Results}

Disease resistance of $\mathbf{E}+$ and $\mathbf{E}$ - plants in the climate chamber In 2004, powdery mildew (B. graminis) incidence on $\mathrm{E}+$ and $\mathrm{E}-$ $A$. inebrians was similar under a soil moisture content of both 30 and $50 \%$ WHC. In 2005, incidence was again similar at $30 \%$ WHC but at $50 \%$ WHC disease incidence on $\mathrm{E}+$ declined by $49 \%$ and was significantly $(\mathrm{P}<0.05)$ lower than on E- plants (Fig. 1).

\section{Disease resistance of $\mathrm{E}+$ and $\mathrm{E}$ - plants in the field}

In the field, the existence of $N$. gansuense did not significantly affect the incidence, severity and leaf lesion number of leaf spot (B. sorokiniana) on A. inebrians ( $\mathrm{P}>0.05)$ (Fig. 2).

\section{Pest resistance of $\mathrm{E}+$ and $\mathrm{E}$ - plants}

In the climate chamber, regardless of drought ( $30 \% \mathrm{WHC}$ ) or normal ( $50 \% \mathrm{WHC}$ ) soil conditions, the density of $T$. cinnabarinus on E+ plants was significantly $(\mathrm{P}<0.05)$ lower than that on E- plants. Mite levels were highest under drought conditions (Fig. 3).

In the field, the densities of $R$. padi on E+ plants were significantly $(\mathrm{P}<0.05)$ lower than that on E- plants (Fig. 4), as was the case for T. cinnabarinus (Fig. 5).

\section{Discussion}

Epichloë endophytes (Neotyphodium and Epichloë spp.) may enhance the abilities of grasses to resist pathogens by inhibiting sporulation (Li 2005) and spore germination (Holzmann-Wirth et al. 2000), preventing invasion and colonisation, delaying or reducing subsequent lesion development (Nan \& Li 2000 2004), and deterring virus-vector insects as well (West et al. 1990; Latch 1993). Many studies have shown that pure cultures of many epichloë endophytes inhibit growth of plant-pathogenic fungi (White \& Cole 1985; Christensen \& Latch 1991; HolzmannWirth et al. 2000; Siegel \& Latch 1989).

In the climate chamber pot trial, effects of endophytes of $A$. inebrians on powdery mildew varied according to the environment (Fig. 1), but in the field neither incidence nor severity of Bipolaris leaf spot was affected by endophyte infection (Fig. 2). Other researchers have reported some instances of enhanced disease resistance with Neotyphodium or Epichloë infection, but not always (Siegel \& Latch 1991; Latch 1993; Nan \& Li 2004; Popay \& Bonos 2005). For example, tall fescue (Festuca arundinacea) seedling stem rust (Puccinia graminis subsp. graminicola) infection was unaffected by $N$. coenophialum infection under glasshouse conditions (Welty et al. 1991). Also, N. coenophialum did not reduce tall fescue root rot by Cochliobolus sativus (Trevathan 1996), root disease by Pythium aphanidermatum (Blank et al. 1993) or foot rot by Fusarium oxysporum and F. equiseti (Hume et al. 1997). A few studies indicated that endophytes could improve resistance to diseases such as turfgrass blight caused by Pythium (Funk et al. 1994), purple spot on timothy grass caused by Cladosporium phlei (Shimanuki 1987), seedling disease of tall fescue caused by Rhizoctonia zeae (Gwinn \& Gavin 1992), and dollar spot caused by Sclerotinia homeocarpa (Clarke et al. 2006). Also, detached leaves of E+ Elymus cylindricus had fewer and smaller lesions than those on E- plants 3 days after inoculation with A. alternata, $F$. avenaceum, F. culmorum, F. equiseti and F. oxysporum (Nan 
\& Li 2000). E+ tall fescue plants were more resistant to crown rust (P. coronata) under field conditions (West et al. 1989) and $N$. lolii infected perennial ryegrass plants were observed to be more resistant to leaf spot (Pyrenophora semeniperda) than uninfected plants (Wheatley et al. 2000).

Grass disease resistance is influenced by many biotic and nonbiotic factors, including variety, pathogen type, environmental conditions, endophyte status and so on (Siegel \& Latch 1991; Latch 1993). Our research showed variation of powdery mildew incidence between $30 \%$ and $50 \%$ WHC soil conditions, and between $\mathrm{E}+$ and E- plants (Figs. 1 \& 2). Moreover, different isolates may produce different quantities and types of antifungal substances and some probably confer different agronomic characters on the host plant (Christensen \& Latch 1991). Two isolates of N. uncinatum and three of four isolates of Epichloë festucae gave no inhibition of $D$. erythrospila and $R$. zeae (Christensen 1996).

This is the first report of an evaluation of endophytic grass resistance to pests in China. Our results showed that Neotyphodium infection could significantly $(\mathrm{P}<0.05)$ reduce densities of $R$. padi and $T$. cinnabarinus on $\mathrm{E}+A$. inebrians compared to $\mathrm{E}$ - plants (Fig. 3-5). At least four species of aphids are deterred by grass endophytes: Diuraphis noxia, R. padi, Schizaphis graminum and Sipha flava (Siegel et al. 1990; Latch 1993; Schardl \& Phillips 1997), but only one species of Acarina mites, Abacarus hystrix (Li \& Nan 2004). This trial shows another mite, T. cinnabarinus is deterred by endophytic A. inebrians. High levels of two main ergot alkaloids, ergonovine and ergine, are produced in endophytic A. inebrians (Miles et al. 1996; Li et al. 2006). Of the more than 10 known alkaloids associated with grass endophytes, peramine and loline have proved more toxic to insects than have ergot alkaloids and indolediterpenes (Bacon 1995; Schardl \& Phillips 1997; Faeth \& Bultman 2002). It is possible the very high levels of ergot alkaloids or other substances produced in the interactions between $A$. inebrians and $N$. gansuense, deterred $R$. padi and T. cinnabarinus. Future studies to elucidate the chemical basis for invertebrate deterrence would be of considerable practical importance for the use or manipulation of endophytes as bioprotective agents.

\section{ACKNOWLEDGEMENTS}

We thank graduate students Xiaoyuan Gou, Jiahui Gao, Pei Tian, Bin Ma and Bin Nie for partial assistance. This research was financially supported by the National High Technology Research and Development Program of China (2004AA244080), Gansu Middle and Young Scientist Foundation (3ZS041-A25-003) and National Nature Science Foundation of China (30070546).

\section{REFERENCES}

Bacon, C.W. 1995. Toxic endophyte-infected tall fescue and range grasses. Historic perspectives. Journal of Animal Science 73: 861-870.

Blank, C.A.; Gwinn, K.D.; Gavin, A.M. 1993. Tolerance of tall fescue to soilborne pathogens is influenced by Acremonium coenophialum. pp. 145-150. In: Proceedings of the 2nd International Symposium on Acremonium/Grass Interactions.

Christensen, M.J.; Latch, G.C.M. 1991. Variation among isolates of Acremonium endophytes (A. coenophialum and possibly A. typhinum) from tall fescue (Festuca arundinacea). Mycological Research 95: 1123-1126.

Christensen, M.J. 1996. Antifungal activity in grasses infected with Acremonium and Epichloë endophytes. Australisian
Plant Pathology 25: 186-191.

Christensen, M.J.; Latch, G.C.M.; Tapper, B.A. 1991. Variation within isolates of Acremonium endophytes from perennial ryegrasses. Mycological Research 95: 918-923.

Clarke, B.B.; White, J.F.; Hurley, R.H.; Torres, M.S.; Sun, S.; Huff, D.R. 2006. Endophyte-mediated suppression of dollar spot disease in fine fescues. Plant Disease 90: 994-998.

Faeth, S.H.; Bultman, T.L. 2002. Endophytic fungi and interactions among host plants, herbivores and natural enemies. pp. 89-123. In: Multitrophic Level Interactions. Eds. Tscharnfre T.; Hawkins B.A. Cambridge University Press, Cambridge, UK.

Funk, C.R.; Belanger, F.C.; Murphy, J.A. 1994. Role of endophytes in grasses used for turf and soil conservation. pp. 201-208. In: Biotechnology of Endophytic Fungi of Grasses. Eds. Bacon C.W.; White J.F. CRC Press, Florida, USA.

Gwinn, K.D.; Gavin, A.M. 1992. Relationship between endophyte infestation level of tall fescue seed lots and Rhizoctonia zeae seedling disease. Plant Disease 76: 911-914.

Holzmann-Wirth, A.; Dapprich, P.; Eierdanz, S.; Heerz, D.; Paul, V.H. 2000. Anti-fungal substances extracted from Neotyphodium endophytes. pp. 65-69. In: Proceedings of the $3^{\text {rd }}$ International Conference on Harmful and Beneficial Microorganisms in Grassland, Pasture and Turf.

Hume, D.E.; Quigley, P.E.; Aldaoud, R. 1997. Influence of Neotyphodium infection on plant survival of diseased tall fescue and ryegrass. pp. 171-173. In: Neotyphodium/Grass Interactions. Eds. Bacon C.W. and Hill N.S. Plenum Press, New York, USA.

Latch, G.C.M. 1993. Physiological interactions of endophytic fungi and their hosts. Biotic stress tolerance imparted to grasses by endophytes. Agriculture, Ecosystems and Environment 44: 143-156.

Li, C.J. 2005. Biological and ecological characteristics of Achnatherum inebrians / Neotyphodium endophyte symbiont. PhD Dissertation, Lanzhou University, China.

Li, C.J.; Gao, J.H.; Ma, B. 2003. Seven diseases of drunken horse grass (Achnatherum inebrians) in China (In Chinese with English abstract). Pratacultural Science 20 (11): 51-53.

Li, C.J.; Nan, Z.B.; Gao, J.H.,; Tian, P. 2004a. Detection and distribution of Neotyphodium - Achnatherum inebrians association in China. \#210. In: Proceedings of $5^{\text {th }}$ International Symposium on Neotyphodium/Grass Interactions, Fayetville, Arkansas.

Li, C.J.; Nan, Z.B.; Volker, H.P.; Dapprich, P.; Liu, Y. 2004b. A new Neotyphodium species symbiotic with drunken horse grass (Achnatherum inebrians) in China. Mycotaxon 90: 141-147.

Li, C.J.; Nan, Z.B.; Schardl, C.L. 2006. Levels and temporal variation of ergot alkaloids in endophyte-infected drunken horse grass, Achnatherum inebrians, in China. pp. 203-204. In: APS, CPS and MSA Joint Meeting Abstracts, Quebec City, Canada.

Miles, C.O.; Lane, G.A.; Menna, M.E.; Garthwaite, I.; Piper, E.L.; Ball, O.J.P.; Latch, G.C.M.; Allen, J.M.; Hunt, M.B.; Bush, L.P.; Feng, K.M.; Fletcher, I.; Harris, P.S. 1996. High levels of ergonovine and lysergic acid amide in toxic Achnatherum inebrians accompany infection by an Acremonium-like endophytic fungus. Journal of Agriculture and Food Chemistry 44: 1285-1290.

Nan, Z.B.; Li, C.J. 2000. Neotyphodium in native grasses in China and observations on endophyte/host interactions. pp. 41-50. In: Proceedings of $4^{\text {th }}$ International Neotyphodium /Grass Interactions Symposium, Eds. Volker, H.P. and Dapprich, P.D. Soest Germany. 
Nan, Z.B.; Li, C.J. 2004. Roles of the grass-Neotyphodium association in pastoral agriculture systems. Acta Ecologica Sinica 24: 605-616.

Popay, A.J.; Baltus, J.G.; Pennell C.G.L. 2000. Insect resistance in perennial ryegrass infected with toin-free Neotyphodium endophytes. pp. 187-193. In: Proceedings of $4^{\text {th }}$ International Neotyphodium /Grass Interactions Symposium, Eds. Volker, H.P. and Dapprich, P.D. Soest, Germany.

Popay, A.J.; Bonos, S.A. 2005. Biotic responses in endophytic grasses. pp. 163-185. In: Neotyphodium in Cool-season Grasses. Eds. Roberts C.A.; West, C.P.; Spiers, D.E. Arkansas, USA.

Schardl, C.L.; Phillips, T.D. 1997. Protective grass endophytes where are they from and where are they going? Plant Disease 81: 430-438.

Shimanuki, T. 1987. Studies on the mechanisms of the infection of timothy with purple spot disease caused by Cladosporium phlei (Gregory) de Vries. Research Bulletin of the Hokkaido National Agricultural Experiment Station 148: 1-5.

Siegel, M.R.; Latch, G.C.M. 1989. Expression of antifungal activity in agar culture by isolates of grass endophytes. Mycologia 83: 529-537.

Siegel, M.R.; Latch, G.C.M.; Bush, L.P.; Fannin, N.F.; Rowan, D.D.; Tapper, B.A.; Bacon, C.W.; Johnson, M.C. 1990. Fungal endophyte-infected grasses: alkaloid accumulation and aphid response. Journal of Chemical Ecology 16: 3301-3315.

Siegel, M.R.; Latch, G.C.M.; Johnson, M.C. 1987. Fungal endophytes of grasses. Annual Review of Phytopathology 25: 293-315.
Trevathan, L.E. 1996. Performance of endophyte-free and endophyte-infected tall fescue seedlings in soil infected with Cochliobolus sativus. Canadian Journal of Plant Pathology 18: 415-418.

Welty, R.E.; Barker, R.E.; Azevedo, M.D. 1991. Reaction of tall fescue infected and noninfected by Acremonium coenophialum to Puccinia graminis subsp. graminicola. Plant Disease 75: 883-886.

West, C.P.; Gwinn, K.D. 1993. Role of Acremonium in drought, pest and disease tolerances of grasses. pp. 1130. In: Proceedings of the $2^{\text {nd }}$ International Symposium on Acremonium/Grass Interactions.

West, C.P.; Izekor, E.; Robbins, R.T.; Gergerich, R.; Mahmood, T. 1990. Acremonium coenophialum effects on infestations of barley yellow dwarf virus and soil-borne nematodes and insects in tall fescue. pp. 196-198. In: Proceedings of International Symposium on Neotyphodium/Grass Interactions.

West, C.P.; Turner, K.; Phillips, J.M. 1989. Arkansas report. pp. 23-25. In: Proceedings of Tall fescue Toxicosis Workshop.

Wheatley, W.M.; Nicol, H.I.; Hunt, E.R.; Nikandrow, A.; Cother, N. 2000. An association between perennial ryegrass endophyte, a leafspot caused by Pyrenophora semeniperda and preferential grazing by sheep. pp. 71-75. In: Proceedings of The $3^{\text {rd }}$ International Conference on Harmful and Beneficial Microorganisms in Grassland, Pasture and Turf.

White, J.F.; Cole, G.T. 1985. Endophyte-host association in forage grasses. III. In vitro inhibition of fungi by Acremonium coenophialum. Mycologia 77: 487-489. 